\title{
SARS-CoV-2: its potential neurological manifestations and plausible mechanism: a review article
}

\author{
Tasneem Taher $^{1} \cdot$ Anum Bilal Sheikh ${ }^{1} \cdot$ Farah Anwar $^{1}$ (D) Faisal Khosa $^{2}$
}

Received: 2 July 2020 / Accepted: 17 December 2020 / Published online: 19 January 2021

(c) Belgian Neurological Society 2021

\begin{abstract}
Coronavirus disease (COVID-19) was first identified in late December 2019. The disease began in Wuhan, Hubei province in China and since then it has spread quickly to many countries all over the world. COVID-19 is caused by a novel coronavirus, named severe acute respiratory syndrome coronavirus 2 (SARS-CoV-2). The virus was majorly seen to overwhelm the respiratory system with mild to severe acute respiratory syndrome considered pathognomic for the disease. However, with time a plethora of symptoms was observed in the patients infected with COVID-19 including strong evidence for neurological symptoms. Evidence suggests that the virus has both central and peripheral nervous system manifestations. Patients, particularly those who suffer from a severe illness, have a central nervous system (CNS) involvement and neurological manifestations. There is precise and targeted documentation of neurological symptoms with details of clinical, neurological, and electrophysiological findings. This review article thus gives an insight into the neuro-invasive potential of COVID-19 and discusses the possible pathogenesis.
\end{abstract}

Keywords Nervous system · COVID-19 · CNS · PNS · Coronavirus · Pathway

\begin{tabular}{|c|c|c|c|}
\hline \multicolumn{2}{|c|}{ Abbreviations } & EEG & Electroencephalogram \\
\hline $\mathrm{ACE}$ & Angiotensin-converting enzyme & GBS & Guillain Barre Syndrome \\
\hline ACE2 & Angiotensin-converting enzyme 2 & $\mathrm{HCoV}$ & Human coronavirus \\
\hline Ach & Acetylcholine & IL-6 & Interleukin-6 \\
\hline AIDP & $\begin{array}{l}\text { Acute inflammatory demyelinating } \\
\text { neuropathy }\end{array}$ & $\begin{array}{l}\text { MERS } \\
\text { MERS-CoV }\end{array}$ & $\begin{array}{l}\text { Middle East Respiratory Syndrome } \\
\text { Middle East Respiratory Syndrome }\end{array}$ \\
\hline AMAN & Acute motor axonal neuropathy & & Coronavirus \\
\hline CNS & Central nervous system & $\mathrm{nAChR}$ & Nicotinic acetylcholine receptor \\
\hline COPD & Chronic obstructive pulmonary disease & PNS & Peripheral nervous system \\
\hline $\mathrm{CoV}$ & Coronavirus & RNA & Ribonucleic acid \\
\hline COVID-19 & Coronavirus disease 2019 & SARS & Severe Acute Respiratory Syndrome \\
\hline CoVs & Coronaviruses & SARS-CoV-2 & Severe Acute Respiratory Syndrome \\
\hline CSF & Cerebrospinal fluid & & Coronavirus 2 \\
\hline CVD & Cerebrovascular disease & TMPRSS & Transmembrane serine protease \\
\hline CVE & Cerebrovascular event & $\begin{array}{l}\mathrm{TNF} \\
\beta \mathrm{CoV}\end{array}$ & $\begin{array}{l}\text { Tumour necrosis factor } \\
\text { Beta coronavirus }\end{array}$ \\
\hline
\end{tabular}

Faisal Khosa: Dr. Khosa is the recipient of the AFMC-May Cohen Equity, Diversity and Gender Award (2020).

Farah Anwar

farah.anwerkhan@gmail.com

1 Department of Internal Medicine, Dow University of Health Sciences, Karachi, Pakistan

2 Department of Radiology, University of British Columbia, Vancouver, BC, Canada

\section{Introduction}

There was a sudden spike in the cases of pneumonia, most of unknown etiology, in late December 2019 in Wuhan, Hubei province in China, with an epidemiological link to the Huanan Seafood Wholesale Market [1]. It appears that most of the early cases had contact history with the original 
seafood market suggesting animal to human transmission; however, the global spread of the disease has largely been due to human-to-human contact [2].

Initially referred to as "2019-nCoV" and "Wuhan coronavirus", on February 11, 2020, the virus strain was officially termed "severe acute respiratory syndrome coronavirus 2 " (SARS-CoV-2). However, the WHO officially renamed the disease as "coronavirus disease 2019" (COVID-19) [3].

Genomic analysis shows that COVID-19 is in the betacoronavirus $(\beta \mathrm{CoV})$ clade as SARS-CoV and MERS-CoV, which also infected the human population in this century [4]. COVID-19 shares at least 70\% similarity in genetic sequence to SARS-CoV. [1]. Many SARS-related coronaviruses ( $\mathrm{SARSr}-\mathrm{CoVs}$ ) have been discovered in bats which is their natural reservoir host. A study suggests that COVID-19 is $96 \%$ identical at the whole-genome level to a bat coronavirus [2].

Initially presenting as a febrile respiratory illness, the typical clinical symptoms of COVID-19 patients are fever, dry cough, breathing difficulties (dyspnea), headache, pneumonia which may progress to respiratory failure owing to alveolar damage [2]. COVID-19 exploits the angiotensinconverting enzyme 2 (ACE2) receptor to gain entry inside the cells and hence invades the human respiratory tract due to the presence of ACE2 receptors that are present abundantly in the epithelia of the lungs [3,5].

However, there have been reports of COVID-19 patients exhibiting only neurological symptoms as their initial symptoms, such as headache, languidness, unstable gait, and malaise [6].

There is also evidence of several neurological complications of the virus, including polyneuritis, Guillain-Barre syndrome (GBS), meningitis, encephalomyelitis, and encephalopathy [3]. In the current outbreak, a study conducted in a hospital in China involving 214 patients, reported neurological manifestations in $78(36.4 \%)$ patients with COVID-19 [7].

There is evidence of neurological tissue expression of ACE2 receptors in the brain, detected over the glial cells and neurons, which makes them a potential target of COVID19 [3]. Also, the neuroinvasive potential of CoVs has been previously documented for almost all the $\beta \mathrm{CoVs}$, including SARS-CoV, MERS-CoV, and others [4].

To further our rationale of the neurotropic potential of the COVID-19 virus, and to summarise the neurological findings discussed in the previous studies and case reports so that a clinician can get an overview of all the previous literature by going through a single article, we aim to describe the neurological manifestations of COVID-19.

\section{Methodology}

An extensive literature search was conducted using Pubmed and Google Scholar. In both electronic databases, the following search strategy was implemented and these keywords (in the abstract) were used: 'COVID-19' AND 'CNS' OR 'PNS' OR 'Nervous system'. The aim was to include all the various CNS and PNS findings in one document so the documents which reported similar manifestations were excluded. No specific time frame was selected, however, most of the articles were from 2020 and a few articles from previous years regarding SARS and MERS were also included. To ensure literature saturation, the reference lists of the included studies were thoroughly scanned for other relevant articles. The three authors actively participated in writing the article and then critically reviewing it at the end. The neurological manifestations discussed below are summarized in Table 1 .

\section{Central nervous system (CNS) manifestations of SARS-CoV2}

\section{Encephalitis}

Encephalitis refers to inflammation of the brain parenchyma and is characterized by symptoms of headache, fever, vomiting, convulsions, and altered sensorium. The association

Table 1 Overview of COVID-19's impact on the central and peripheral nervous systems

\begin{tabular}{|c|c|c|}
\hline & CNS overview of COVID-19 & PNS overview of COVID-19 \\
\hline Mode of transmission & $\begin{array}{l}\text { Directly: via respiratory droplets } \\
\text { Indirectly: via contact with contaminated surfaces }\end{array}$ & $\begin{array}{l}\text { Directly: via respiratory droplets } \\
\text { Indirectly: via contact with contaminated surfaces }\end{array}$ \\
\hline Pathophysiology theories & $\begin{array}{l}\text { Infection induced cytokine storm } \\
\text { Dysfunction of brain ACE- } 2 \text { receptors } \\
\text { Entrance via the peripheral nerves and retrograde flow to } \\
\text { the CNS }\end{array}$ & $\begin{array}{l}\text { Direct entry into the peripheral nerves such as the olfac- } \\
\text { tory nerve } \\
\text { Demyelination of nerves }\end{array}$ \\
\hline Symptoms ${ }^{\mathrm{a}}$ & $\begin{array}{l}\text { Encephalitis, Encephalopathy, Acute cerebrovascular dis- } \\
\text { ease, Acute respiratory failure due to brain dysfunction, } \\
\text { Guillian-Barre syndrome, Seizures, Headache }\end{array}$ & $\begin{array}{l}\text { Olfactory and gustatory dysfunction, Oculomotor nerve } \\
\text { palsy }\end{array}$ \\
\hline
\end{tabular}

${ }^{a}$ Limitations are prevalent as much research is needed in this area 
between viral encephalitis and COVID-19 was revealed when the treatment team at Beijing Ditan Hospital detected the presence of SARS-CoV-2 in the cerebrospinal fluid (CSF) of patients diagnosed with COVID-19 [8]. The same virus was also isolated from the CSF of a patient in Japan who had clinically proven meningoencephalitis, as well as a 56-year old woman in Wuhan who was diagnosed with encephalitis, hence reiterating the association $[9,10]$

Another Wuhan male was also diagnosed with encephalitis associated with SARS-CoV-2 infection based on physical evaluation of the neurological symptoms though the CSF specimen did not indicate the presence of SARS-CoV-2. The negative results are assumed to be because the dissemination of the virus is transient, and the CSF titers are too low for the virus [11].

It is believed that the presence of pro-inflammatory cytokines in the CSF increases the permeability of the blood-brain barrier and thus allows the virus to invade the CNS and produce neurological manifestations [12].

\section{Encephalopathy}

Encephalopathy is a type of reversible brain dysfunction syndrome, with no evidence of inflammation on CSF analysis, which is potentially caused by factors such as toxemia, hypoxia, and viral infection. Guo et al. mentioned that COVID-19 causes viremia and hypoxia, so it can be conjectured that COVID-19 is a potential cause of encephalopathy [8].

It was also suggested that elderly patients with pre-existing conditions, respiratory distress, and prior neurological symptoms had a higher potential of presenting with encephalopathy due to COVID-19 infection. There is evidence of a 74-year-old male patient with a past medical history of cardioembolic stroke, atrial fibrillation, chronic obstructive pulmonary disease (COPD), Parkinson's disease, and recent cellulitis that tested positive for COVID-19 and was simultaneously diagnosed with encephalopathy [13]. Another case of a 58-year-old COVID-19 positive female was diagnosed with acute necrotizing encephalopathy, the most probable cause of which was infection-induced cytokine storm [12]. Helms et al. also observed a person with electroencephalography findings consistent with encephalopathy while studying neurological signs and symptoms in COVID-19 patients [14].

Therefore, physicians should consider COVID-19 in the differential diagnosis in patients presenting with confusion, lethargy, and strange behavior.

\section{Acute cerebrovascular disease}

Out of the 37 studies used in a comparative review, 370 patients with SARS-CoV2 infection were reported to have an acute ischemic stroke or transient ischemic attack. These patients were those who already had certain co-morbidities which put them at an increased risk of thromboembolic events [15].

\section{Cerebral hemorrhage}

A 79-year-old male patient with a confirmed COVID-19 infection had presented with intracerebral hemorrhage accompanied with intraventricular and subarachnoid hemorrhage that was hypothesized to be because of dysfunction of brain ACE2 receptors which thereby led to the disruption of autoregulation and resulted in high blood pressure and arterial wall rupture [16].

The same hypothesis is further supported in another study which stated that hypertensive patients who already have reduced expression of ACE2 receptors are more prone to develop intracerebral hemorrhage when infected with SARS$\mathrm{CoV}-2$ because the latter further reduces the expression and function of ACE2 proteins [6].

A prospective study by Di Castelnuovo et al. described the relationship between intracerebral hemorrhage and elevated D-dimer levels in which he stated that D-dimers lead to fibrinolysis and a resultant hypocoaglable state which predisposes to hemorrhages [17]. Since severely ill COVID-19 patients have elevated levels of D-dimers [8], this is a plausible mechanism for the development of cerebral hemorrhages.

This endothelial rupture in cerebral arteries and capillaries occurs long before the neuronal damages and can have fatal consequences due to bleeding within the cerebral tissues [3].

Patients infected with COVID-19 sometimes suffer from coagulopathy and prolonged prothrombin time which further suggests that the virus can lead to secondary cerebral hemorrhages $[18,19]$.

\section{Ischemic stroke}

A report described a patient with a complaint of right limb weakness who was later diagnosed with COVID-19. It is suggested that the infection caused hypoxemia and release of inflammatory cytokines that led to the development of ischemic stroke which was causative of the right limb weakness [20].

In a study by Oxley et al. five COVID-19 positive patients who were under the age of 50 and who had no previous history of cerebrovascular accidents presented with large-vessel stroke. After excluding all other probable causes, their stroke was attributed to COVID-19 infection [21]. This suggests that middle-aged and healthy patients are at an equal risk of COVID-19 induced stroke similar to the elderly and severely ill patients. 
A previous study suggests that COVID-19 infection induces a cytokine storm, which may be one of the causes for the development of CVD [22].

Moreover, severely ill patients infected with COVID-19 have elevated levels of D-dimers and a reduced platelet count which may make them more susceptible to acute CVD [8].

CVD in the form of secondary cerebral infarctions has also been reported in SARS and hence it is anticipated that the same might occur in COVID-19 infection [6].

\section{Acute respiratory failure due to loss of brain function}

Given the previous studies that report the neuro-invasive potential of COVID-19 [7], it is conjectured that the respiratory failure reported in COVID-19 patients might be due to damage of the respiratory center in the medulla as the latency period of 8 days from the first symptoms to intensive care might be enough to destroy the medullary neurons [4]. The lack of dyspnea observed in severe cases of COVID-19 patients further supports the fact that the respiratory failure is due to neuronal involvement and not merely due to viral pneumonia because the pulmonary $\mathrm{C}$ fibers that play a role in dyspnea are damaged due to the infection-induced cytokine storm [23].

A finding published on a patient who had a loss of involuntary control over breathing was found to be different from the acute respiratory failure reported in several patients as the former was because of neuroinvasion and not because of pneumonia and thus physicians should be able to differentiate between the neurologically affected patients and those who are devoid of any neurological manifestations [3].

However, another study states that respiratory failure is not due to brain dysfunction as the latter causes type 2 respiratory failures unlike the type 1 respiratory failure found in COVID-19 infected patients [24].

\section{Guillain-Barre syndrome}

A patient infected with COVID-19 was diagnosed with GBS and it was speculated that the viral infection had led to the development of demyelinating neuropathy. This was the first such case that came to attention [25]. Two more variants of GBS, Miller Fisher syndrome and polyneuritis cranialis, that characteristically affect the ocular muscles were further diagnosed among two patients. [26]. A literature review later presented by Ahmed I et al. also discussed many more cases of COVID-19 infected patients who developed GBS thereby proving a vivid association between COVID-19 and GBS [27].

\section{Seizures}

The presence of seizures in COVID-19 patients was first reported by Moriguchi and his colleagues. A 24-year-old male patient, who was brought to the hospital due to a convulsion followed by unconsciousness, developed transient generalized seizures. He was later diagnosed with aseptic encephalitis and his cerebrospinal fluid tested positive for SARS-CoV-2 RNA [9].

A 30-year-old female, previously in her usual healthy state was reported to present with generalized tonic-clonic seizures. According to the patient she had seizures at a frequency of five times every eight hours. She tested positive for COVID-19 using real-time PCR assay. Her brain MRI was normal. However, her symptoms improved with anticonvulsive and antiviral medications. [28]

Subclinical seizures were documented with critical illness [29]. Studies indicate that those with existing primary seizure disorder are at higher risk of seizures and status epilepticus in the setting of severe infection [30]. In their research, Zubair et al. reported a high proportion of breakthrough seizures in patients with epilepsy who developed COVID-19 [31].

\section{Miscellaneous}

A study conducted among patients in Wuhan reported neurological manifestations in 78 out of 214 patients diagnosed with COVID-19 amongst which the most common complaints were dizziness and headaches [7]. In another survey conducted among physicians in Italy, $82 \%$ of them observed neurological symptoms among COVID-19 patients amongst which the most common reported symptoms were headaches, myalgias, and taste and smell abnormalities [32].

Headache was a very frequent complaint among patients; $34 \%$ of the patients in a study in Zhejiang complained of headaches [33]. Recently, it was reported as a predominant complaint in a case series, along with fever, cough, sore throat, and breathlessness [34]. There is variation in the prevalence of headache in different reports, however, it can affect up to one-third of diagnosed patients [35].

Neurological symptoms including vomiting and delirium were also present in many patients [36]. Studies have reported that neurological symptoms are significantly more common among the more severely ill patients [7].

Ping Wu et al. reported various ocular symptoms in patients including conjunctivitis, conjunctival hyperemia, chemosis, epiphora, and increased secretions. Of the 38 clinically confirmed cases of COVID-19 in their study, 2 patients yielded positive results on RT-PCR, for SARS-CoV 2 in their conjunctival specimen [37].

Although most of the specific, as well as non-specific neurological manifestations, have been reported among the 
elderly population, a study in France reported four COVID19 positive infants who presented with atypical findings such as axial hypotonia, drowsiness, and moaning [38].

\section{Peripheral nervous system (PNS) manifestations of SARS-CoV2}

\section{Oculomotor nerve palsy}

A case study revealed acute unilateral isolated oculomotor nerve palsy in a 62-year-old male who presented with a drooping left eye and diplopia. Health care providers tested him for common causes of third nerve palsy including an aneurysm, GBS, diabetes complication, tumor which were all negative. Although the typical COVID-19 symptoms of fever, cough, and dyspnea were initially absent, he eventually tested positive for the disease which led the medical team to attribute this palsy to SARS-CoV-2 infection [39].

In another case report, Dinkin et al. discussed two patients who presented with ophthalmoparesis and diplopia after experiencing COVID-19 symptoms. This provides further evidence that is supportive of the association between COVID-19 infection and oculomotor nerve palsy [40].

\section{Olfactory and gustatory dysfunction}

Many cases of altered sense of smell and taste were reported in COVID-19 patients. These include symptoms ranging from dysgeusia, dysosmia to ageusia, and anosmia. These terms refer to an altered sense of taste and smell and these symptoms have been attributed to olfactory and trigeminal nerve damage, in the form of inflammation or receptor damage, due to COVID-19 infection and also to the increased use of disinfectants by the people during the viral epidemic [41]. However, the exact mechanism of damage requires further investigation.

In a study conducted among hospitalized patients in Wuhan, the prevalence of hypogeusia and hyposmia was 5.6 and $5.1 \%$, respectively [7].

Esmaeil et al. in their review article included evidence from various countries such as the USA, UK, Iran, Spain, Italy, China, France, Norway, Switzerland, Cuba, and Denmark. Anosmia was reported in 23 out of the 24 articles reviewed in the study and hence was the most common symptom, establishing strong evidence of a surge in olfactory abnormalities during COVID-19. This was followed by reports of hyposmia, ageusia, and dysgeusia, in order of decreasing frequency [42].

Zubair et.al in their study reported anosmia as an early symptom of COVID-19 and suggested that testing for anosmia might offer a potential early detection of COVID-19 infection [31].

\section{Proposed mechanism of action of SARS-CoV2 infection on the nervous system}

\section{ACE 2}

Perhaps this mechanism is the one that is most commonly discussed in the existing literature; ACE2 is present in many organs of the body such as vessels, brain, lungs, kidneys and has a role in regulating blood pressure by opposing the effects of ACE. ACE is an enzyme responsible for increasing angiotensin II in the body which is a vasoconstrictor, ACE2 acts by catalyzing the breakdown of angiotensin II into the vasodilators angiotensin 1-7. Hence by increasing the vasodilators and reducing the vasoconstrictors ACE2 lowers the blood pressure.

Like SARS-CoV, SARS-CoV-2 uses spike proteins present on its surface to bind with ACE2 [3]. This binding may negatively impact this blood pressure regulating mechanism and predispose the patient to cerebrovascular events (CVE) like hemorrhage and ischemic stroke. Elderly or those with co-morbid conditions like hypertension and a history of stroke are particularly at high risk of these cerebrovascular emergencies [8].

In the brain, ACE2 is found specifically in the brainstem where nuclei responsible for cardiovascular and respiratory activities are present; hence viral interaction with these can have deleterious effects on the normal physiology of both the essential functions [36, 43]. An experimental study also showed their potential presence in glial cells, and viral interaction with these may directly damage neurons [36].

ACE2 was also linked to a possible role in the antiatherosclerosis mechanism by an experimental study conducted on rabbits [44]. So, another consequence of virus-ACE2 binding may be to disrupt this process. In congruence, a study found the levels of D-dimers to be increased in COVID-19 patients attesting to this possibility [45]. Perhaps the CVE is the aftermath of a proatherosclerotic state created by the virus.

More recent studies discuss ACE2 as a point of entry of the virus into the body by calling the human transmembrane serine proteases (TMRSS2 and TMPRSS4) as co-receptors which may enhance the ACE2 and spike protein fusion [46].

\section{Neuronal pathway}

According to this mechanism the SARS-CoV-2 enters peripheral nerves and travels in a trans-synaptic and retrograde fashion to invade the CNS.

The most discussed entrance seems to be through the olfactory nerve because of its unique anatomy. It is 
proposed that intranasal occupancy by the virus results in infection of the olfactory epithelium this is followed by a transcribrial route to reach the olfactory bulb and eventually the CNS. Studies that demonstrate the uptake of the coronaviruses (SARS and MERS) through this pathway in mice are suggestive of this pathway considering the similarities between SARS-CoV-2 and other viruses in the $\mathrm{CoV}$ family [37]. However, recent studies propose that the entry of the virus is not due to direct infection of all cells of olfactory epithelium but it is due to the infection of supporting, non-neuronal cells present in the epithelium which possess ACE2 and transmembrane proteases [47].

Evidence for this neuronal mechanism can be derived from studies conducted on mice in which removal of olfactory bulbs led to a decreased invasion of CNS by CoV [48, 49]. Perhaps the greatest support for this mechanism is the occurrence of dysosmia in COVID-19 affected patients [7].

In addition to the olfactory pathway, which is a wellproven one, some neurologists believe that the oculomotor, trigeminal, vagus and glossopharyngeal nerves likely serve the same purpose $[37,41]$. Once inside the CNS, the virus may cause further injury by initiating demyelination and an inflammatory reaction [8].

Esposito et al. in their letter detail a mechanism that involves the gastrointestinal system. They state that the virus infects the gastrointestinal tract as the epithelium has a high expression of ACE2; from here virus may ascend to CNS via vagal afferent fibers or affect the enteric nervous system [50].

\section{Hypoxia}

This mechanism entails that viral proliferation in the lung parenchyma causes pneumonia which disturbs respiration enough to bring about a general hypoxic state in the body. An anaerobic state is induced owing to the lack of oxygen. This causes a buildup of acid in the brain which develops into cerebral edema and congestion and the resulting intracranial hypertension might be responsible for drowsiness and coma. Since COVID-19 patients often suffer from severe hypoxia, hypoxic injury is thought to be a probable cause of the neurological manifestations seen in this infection [8].

\section{Inflammation related injury}

\section{Cytokine storm due to invasion of immune cells}

It has been suggested that SARS-CoV-2 triggers a systemic inflammatory response syndrome (cytokine storm) which damages the blood-brain barrier leading to CNS infection [36].

The persistence of the $\mathrm{CoV}$ infection and its propensity to invade the immune cells in the brain such as macrophages, glial cells, and astrocytes leads to chronic inflammation and brain damage [8]. An experimental study confirmed that glial cells infected with $\mathrm{HCoV}$ liberate a variety of inflammatory factors including interleukin-6 (IL-6) [49]. In support of this, the anti-IL-6 medicine, tocilizumab, was recently approved for trial and did show some improvement in COVID-19 patients [51]. A similar infection-induced cytokine storm was associated with the development of acute necrotizing encephalopathy, discussed above. It is hypothesized that this widespread pro-inflammatory state causes damage to organs in addition to the nervous system. Muscles are specifically targeted, thereby leading to rhabdomyolysis $[7,45]$.

\section{Cytokine storm due to disruption of the cholinergic pathway}

Recently, a unique theory emerged involving the immune mechanism mentioned above and the cholinergic system. The study first established the importance of the cholinergic pathway in controlling inflammation and preventing an acute immune response. It stated that Acetylcholine (Ach) interacts with nicotinic acetylcholine receptor (nAChRs) $\alpha 7$ subunit present on macrophages and B-lymphocytes inhibiting and limiting the release of TNF and other cytokines. The authors then explained that after infection with SARSCoV-2, cellular debris may attach to and block nAChR impeding the anti-inflammatory function. The resulting unimpeded pro-inflammatory state gives rise to the cytokine storm which leads to acute respiratory distress, coagulation disorders, and eventually multiple organ failure. Coagulation disorders occur because platelets too have the $\alpha 7-\mathrm{AChRs}$.

The study further reinforces this hypothesis by laying down similarities in the amino acid sequence of SARSCoV-2 and snake neurotoxins which also bind to nAChRs. This theory is one of its kind and should be investigated more [52].

\section{Hematogenous}

Soon after the infection, the virus disseminates throughout the body and then neurotropism may occur via the circulation. A study proposed that the presence of a virus in the circulation may result in interaction with the ACE2 receptors on the endothelium of the cerebral capillaries, this may cause viral budding which damages the endothelial linings thereby permitting entry into the CNS [3].

Another study postulates that as some pathogens target the cells of the blood like leukocytes, SARS-CoV-2 may also replicate within these cells and then be released into the blood in a larger amount. This may trigger an immune response that enables infection of CNS by damaging the blood-brain barrier [6]. This barrier is the only thing separating the blood from the CSF, hence the study claiming the 
presence of SARS-CoV in CSF may indicate the potential of coronaviruses to undertake this route [3].

Despite all this, a different study negated the hematogenous spread as an early and primary mechanism alleging that the previously discovered CoVs were not found in nonneuronal tissues in patients who had passed away due to the disease [4]. Given the above contradiction, further studies need to be conducted to affirm the potential of spread of SARS-CoV-2 into the CNS via the hematogenous route.

\section{Conclusion}

Clinical evidence suggests that neurological manifestations in association with COVID-19, are various and prevalent.

To justify the neurological invasion, autopsies of the COVID-19 patients must be performed. Isolates taken from neurological tissues and fluids such as glial cells, neurons, and cerebrospinal fluid, can clarify the role of COVID-19 in nervous system damage.

Patients infected with COVID- 19 have reported coagulopathy, prolonged prothrombin time, evidence of elevated levels of D-dimers, and a reduced platelet count. These changes in blood have also been witnessed with neurological manifestations and need to be studied in more detail to establish their correlation with the severity of symptoms.

As suggested by Abdul Mannan Baig et al., the study of the viral isolates in the area close to the olfactory bulb will help establish whether dysosmia and dysgeusia are due to the route of invasion (transcribrial), olfactory and trigeminal nerve damage, or from the increased use of disinfectants by the people during the viral epidemic as stated in some studies [3].

With reports of type 1 respiratory failure found in COVID-19 infected patients, there is also existing literature on respiratory failure due to breathing problems arising from brain damage in COVID-19 positive individuals [24]. Due to the above-mentioned contradiction, future studies must be conducted to confirm whether the acute respiratory failure is due to brain dysfunction or due to end-stage viral pneumonia.

With significant reports of neurological symptoms in the COVID-19 outbreak, there is an urgent need to understand the neurotropic potential of the COVID-19 virus. Healthcare providers should be on the lookout for neurological signs and symptoms in all patients, belonging to all age groups. Based on the severity of symptoms and the site of damage, treatment modalities must be chosen for the patient's benefit and to reduce the burden on the health care system.

Author contributions TT had the idea for the article and then a thorough literature search was conducted by TT, ABS, and FA. All three authors contributed to the writing of the manuscript. The first draft of the manuscript was written by TT and ABS, and the introduction and conclusion were written by FA. All three authors commented on this version of the manuscript and FA made the suggested changes. FK critically revised the final manuscript and offered improvements.

Funding None.

Data availability Not applicable.

\section{Compliance with ethical standards}

Conflict of interest The authors declare that they have no conflicts of interest.

Ethical approval Our research did not involve any human or animal subjects hence the Institutional Review Board (IRB) waived the need for approval.

Informed consent to participate Not applicable.

Informed consent for publication Not applicable.

\section{References}

1. Hui DS, Azhar IE, Madani TA, Ntoumi F, Kock R, Dar O, Ippolito G, Mchugh TD, Memish ZA, Drosten C, Zumla A, Petersen E (2020) The continuing $2019 \mathrm{nCoV}$ epidemic threat of novel coronaviruses to global health the latest 2019 novel coronavirus outbreak in Wuhan China. Int J Infect Dis 91(264):266. https://doi. org/10.1016/j.ijid.2020.01.009

2. Zhou P, Yang XL, Wang XG, Hu B, Zhang L, Zhang W, Si HR, Zhu Y, Li B, Huang CL, Chen HD, Chen J, Luo Y, Guo H, Jiang RD, Liu MQ, Chen Y, Shen XR, Wang X, Zheng XS, Zhao K, Chen QJ, Deng F, Liu LL, Yan B, Zhan FX, Wang YY, Xiao GF, Shi ZL (2020) A pneumonia outbreak associated with a new coronavirus of probable bat origin. Nature 579:270-273. https:// doi.org/10.1038/s41586-020-2012-7

3. Baig AM, Khaleeq A, Ali U, Syeda H (2020) Evidence of the COVID-19 virus targeting the CNS: tissue distribution, host-virus interaction, and proposed neurotropic mechanisms. ACS Chem Neurosci 11(7):995-998. https://doi.org/10.1021/acschemneu ro.0c00122

4. Li YC, Bai WZ, Hashikawa T (2020) The neuroinvasive potential of SARS-CoV2 may play a role in the respiratory failure of COVID-19 patients. J Med Virol 92:552-555. https://doi. org/10.1002/jmv.25728

5. Hamming I, Timens W, Bulthuis ML, Lely AT, Navis G, van Goor H (2004) Tissue distribution of ACE2 protein, the functional receptor for SARS coronavirus A first step in understanding SARS pathogenesis. Journal Pathol 203(2):631-637. https://doi. org/10.1002/path.1570

6. Wang HY, Li XL, Yan ZR, Sun XP, Han J, Zhang BW (2020) Potential neurological symptoms of COVID-19. Ther Adv Neurol Disord. https://doi.org/10.1177/1756286420917830

7. Mao L, Jin H, Wang M et al (2020) Neurologic manifestations of hospitalized patients with coronavirus disease 2019 in Wuhan, China. JAMA Neurol. https://doi.org/10.1001/jamaneurol .2020 .1127

8. Wu Y, Xu X, Chen Z, Duan J, Hashimoto K, Yang L, Liu C, Yang C (2020) Nervous system involvement after infection with 
COVID-19 and other coronaviruses. Brain Behav Immun. https ://doi.org/10.1016/j.bbi.2020.03.031

9. Moriguchi T, Harii N, Goto J, Harada D, Sugawara H, Takamino J, Ueno M, Sakata H, Kondo K, Myose N, Nakao A, Takeda M, Haro H, Inoue O, Suzuki-Inoue K, Kubokawa K, Ogihara S, Sasaki T, Kinouchi H, Kojin H, Ito M, Onishi H, Shimizu T, Sasaki Y, Enomoto N, Ishihara H, Furuya S, Yamamoto T, Shimada S (2020) A first case of meningitis/encephalitis associated with SARS-Coronavirus-2. Int J Infect Dis. https://doi. org/10.1016/j.ijid.2020.03.062

10. Pennisi M, Lanza G, Falzone L, Fisicaro F, Ferri R, Bella R (2020) SARS-CoV-2 and the nervous system: from clinical features to molecular mechanisms. Int J Mol Sci 21(15):5475. https ://doi.org/10.3390/ijms21155475

11. Ye M, Ren Y, Lv T (2020) Encephalitis as a clinical manifestation of COVID-19. Brain Behav Immun. https://doi. org/10.1016/j.bbi.2020.04.017

12. Poyiadji N, Shahin G, Noujaim D, Stone M, Patel S, Griffith B (2020) COVID-19-associated acute hemorrhagic necrotizing encephalopathy: CT and MRI features. Radiology. https://doi. org/10.1148/radiol.2020201187

13. Filatov A, Sharma P, Hindi F, Espinosa PS (2020) Neurological complications of Coronavirus disease (COVID-19): encephalopathy. Cureus 12(3):e7352. https://doi.org/10.7759/cureus.7352

14. Helms J, Kremer S, Merdji H, Clere-Jehl R, Schenck M, Kummerlen C, Collange O, Boulay C, Fafi-Kremer S, Ohana M, Anheim M, Meziani F (2020) Neurologic features in severe SARS-CoV-2 infection. N Engl J Med. https://doi.org/10.1056/ nejmc 2008597

15. Sharifian-Dorche M, Huot P, Osherov M, Wen D, Saveriano A, Giacomini PS, Antel JP, Mowla A (2020) Neurological complications of coronavirus infection; a comparative review and lessons learned during the COVID-19 pandemic. J Neurol Sci. https://doi. org/10.1016/j.jns.2020.117085

16. Sharifi-Razavi A, Karimi N, Rouhani N (2020) COVID-19 and intracerebral haemorrhage: causative or coincidental? New Microbes New Infect. https://doi.org/10.1016/j.nmni.2020.100669

17. Battaglini D, Brunetti I, Anania P et al (2020) Neurological Manifestations of Severe SARS-CoV-2 infection: potential mechanisms and implications of individualized mechanical ventilation settings. Front Neurol 11:845. https://doi.org/10.3389/fneur.2020.00845

18. Chen Z, Fu J, Shu Q, Chen Y, Hua C, Li F, Lin R, Tang L, Wang T, Wang W, Wang Y, Xu W, Yang Z, Ye S, Yuan T, Zhang C, Zhang Y (2020) Diagnosis and treatment recommendations for pediatric respiratory infection caused by the 2019 novel coronavirus. World J Pediatr. https://doi.org/10.1007/s12519-020-00345 $-5$

19. Wang D, Hu B, Hu C, Zhu F, Liu X, Zhang J, Wang B, Xiang H, Cheng Z, Xiong Y, Zhao Y, Li Y, Wang X, Peng Z (2020) Clinical characteristics of 138 hospitalized patients with 2019 novel coronavirus-infected pneumonia in Wuhan, China. JAMA 323(11):1061-1069. https://doi.org/10.1001/jama.2020.1585

20. Zhai P, Ding Y, Li Y (2020) The impact of COVID-19 on ischemic stroke: a case report. Diagn Pathol 15:78. https://doi.org/10.1186/ s13000-020-00994-0

21. Oxley TJ, Mocco J, Majidi S et al (2020) Large-vessel stroke as a presenting feature of Covid-19 in the young. N Engl J Med 382:e60. https://doi.org/10.1056/NEJMc2009787

22. Mehta P, McAuley D, Brown M, Sanchez E, Tattersall R, Manson J (2020) COVID-19: consider cytokine storm syndromes and immunosuppression. Lancet 395(10229):1033-1034. https://doi. org/10.1016/s0140-6736(20)30628-0

23. Bertran Recasens B, Martinez-Llorens JM, Rodriguez-Sevilla JJ, Rubio MA (2020) Lack of dyspnea in Covid-19 patients; another neurological conundrum? Eur J Neurol. https://doi.org/10.1111/ ene. 14265
24. Turtle L (2020) Respiratory failure alone does not suggest central nervous system invasion by SARS-CoV-2. J Med Virol. https:// doi.org/10.1002/jmv.25828

25. Zhao H, Shen D, Zhou H, Liu J, Chen S (2020) Guillain-Barré syndrome associated with SARS-CoV-2 infection: causality or coincidence? Lancet Neurol 19(5):383-384. https://doi. org/10.1016/s1474-4422(20)30109-5

26. Gutiérrez-Ortiz C, Méndez A, Rodrigo-Rey S, San Pedro-Murillo E, Bermejo-Guerrero L, Gordo-Mañas R, de Aragón-Gómez F, Benito-León J (2020) Miller fisher syndrome and polyneuritis cranialis in COVID-19. Neurology. https://doi.org/10.1212/ wnl.0000000000009619

27. Ahmad I, Rathore FA (2020) Neurological manifestations and complications of COVID-19: a literature review. J Clin Neurosci. https://doi.org/10.1016/j.jocn.2020.05.017

28. Karimi N, Sharifi Razavi A, Rouhani N (2020) Frequent convulsive seizures in an adult patient with COVID-19: a case report. Iran Red Crescent Med J. https://doi.org/10.5812/ircmj.102828

29. Lau SK, Woo PC, Yip CC et al (2006) Coronavirus HKU1 and other coronavirus infections in Hong Kong. J Clin Microbiol. https ://doi.org/10.1128/JCM.02614-05

30. $\mathrm{Li} \mathrm{Y,} \mathrm{Li} \mathrm{H,} \mathrm{Fan} \mathrm{R} \mathrm{et} \mathrm{al} \mathrm{(2016)} \mathrm{Coronavirus} \mathrm{infections} \mathrm{in} \mathrm{the} \mathrm{cen-}$ tral nervous system and respiratory tract show distinct features in hospitalized children. Intervirology. https://doi.org/10.1159/00045 3066

31. Zubair AS, McAlpine LS, Gardin T, Farhadian S, Kuruvilla DE, Spudich S (2020) Neuropathogenesis and neurologic manifestations of the coronaviruses in the age of coronavirus disease 2019: a review. JAMA Neurol. https://doi.org/10.1001/jamaneurol .2020 .2065

32. Campiglio L, Priori A (2020) Neurological symptoms in acute COVID-19 infected patients: a survey among Italian physicians. PLoS ONE. https://doi.org/10.1371/journal.pone.0238159

33. Liu K, Pan M, Xiao Z, Xu X (2020) Neurological manifestations of the coronavirus (SARS-CoV-2) pandemic 2019-2020. J Neurol Neurosurg Psychiatry. https://doi.org/10.1136/jnnp-2020-323177

34. Gupta N, Agrawal S, Ish P et al (2020) Clinical and epidemiologic profile of the initial COVID-19 patients at a tertiary care centre in India. Monaldi Arch Chest Dis. https://doi.org/10.4081/monal di.2020.1294

35. Borges do Nascimento IJ, Cacic N, Abdulazeem HM et al (2020) Novel coronavirus infection (COVID-19) in humans: a scoping review and meta-analysis. J Clin Med. https://doi.org/10.3390/ jcm9040941

36. Steardo L, Zorec R, Verkhratsky A (2020) Neuro infection may contribute to pathophysiology and clinical manifestations of COVID-19. Acta Physiol. https://doi.org/10.1111/apha.13473

37. Wu P, Duan F, Luo C, Liu Q, Qu X, Liang L, Wu K (2020) Characteristics of ocular findings of patients with coronavirus disease 2019 (COVID-19) in Hubei Province, China. JAMA Ophthalmol. https://doi.org/10.1001/jamaophthalmol.2020.1291

38. Nathan N, Prevost B, Corvol H (2020) Atypical presentation of COVID-19 in young infants. Lancet 395(10235):1481. https://doi. org/10.1016/S0140-6736(20)30980-6

39. Wei H, Yin H, Huang M, Guo Z (2020) The 2019 novel coronavirus pneumonia with onset of oculomotor nerve palsy: a case study. J Neurol 267(5):1550-1553. https://doi.org/10.1007/s0041 5-020-09773-9

40. Dinkin M, Gao V, Kahan J, Bobker S, Simonetto M, Wechsler $\mathrm{P}$ et al (2020) COVID-19 presenting with ophthalmoparesis from cranial nerve palsy. Neurology 95(5):221-223. https://doi. org/10.1212/wnl.0000000000009700

41. Keyhan SO, Fallahi HR, Cheshmi B (2020) Dysosmia and dysgeusia due to the 2019 novel coronavirus; a hypothesis that needs further investigation. Maxillofacial plastic and reconstructive surgery 42(1):9. https://doi.org/10.1186/s40902-020-00254-7 
42. Mehraeen E, Behnezhad F, Salehi MA, Noori T, Harandi H, SeyedAlinaghi S (2020) Olfactory and gustatory dysfunctions due to the coronavirus disease (COVID-19): a review of current evidence. Eur Arch Otorhinolaryngol. https://doi.org/10.1007/ s00405-020-06120-6

43. Netland J, Meyerholz DK, Moore S, Cassell M, Perlman S (2008) Severe acute respiratory syndrome coronavirus infection causes neuronal death in the absence of encephalitis in mice transgenic for human ACE2. J Virol 82(15):7264-7275. https://doi. org/10.1128/JVI.00737-08

44. Zhang YH, Hao QQ, Wang XY, Chen X, Wang N, Zhu L, Li SY, Yu QT, Dong B (2015) ACE2 activity was increased in atherosclerotic plaque by losartan: possible relation to anti-atherosclerosis. J Renin Angiotensin Aldosterone Syst 16(2):292-300. https://doi. org/10.1177/1470320314542829

45. Jin H, Hong C, Chen S, Zhou Y, Wang Y, Mao L, Li Y, He Q, Li M, Su Y, Wang D, Wang L, Hu B (2020) Consensus for prevention and management of coronavirus disease 2019 (COVID-19) for neurologists. Stroke Vasc Neurol. https://doi.org/10.1136/svn2020-000382

46. Barrantes FJ (2020) Central nervous system targets and routes for SARS-CoV-2: current views and new hypotheses. ACS Chem Neurosci. https://doi.org/10.1021/acschemneuro.0c00434

47. Brann DH, Tsukahara T, Weinreb C, Lipovsek M, Van den Berge K, Gong B, Chance R, Macaulay I, Chou H, Fletcher R, Das D, Street K, de Bezieux HR, Choi Y, Risso D, Dudoit S, Purdom E, Mill JS, Hachem RA, Matsunami H, Logan D, Goldstein B, Grubb MS, Ngai J, Datta SR (2020) Non-neuronal expression of
SARS-Cov-2 entry genes in the olfactory system suggests mechanisms underlying COVID-19-associated anosmia. BioRxiv. https ://doi.org/10.1101/2020.03.25.009084

48. Perlman S, Evans G, Afifi A (1990) Effect of olfactory bulb ablation on spread of a neurotropic coronavirus into the mouse brain. J Exp Med 172(4):1127-1132. https://doi.org/10.1084/ jem.172.4.1127

49. Bohmwald K, Gálvez NMS, Ríos M, Kalergis AM (2018) Neurologic alterations due to respiratory virus infections. Front Cell Neurosci 12:386. https://doi.org/10.3389/fncel.2018.00386

50. Esposito G, Pesce M, Seguella L, Sanseverino W, Lu J, Sarnelli G (2020) Can the enteric nervous system be an alternative entrance door in SARS-CoV2 neuroinvasion? Brain Behav Immun 87:9394. https://doi.org/10.1016/j.bbi.2020.04.060

51. Luo P, Liu Y, Qiu L, Liu X, Liu D, Li J (2020) Tocilizumab treatment in COVID-19: a single center experience. J Med Virol. https ://doi.org/10.1002/jmv.25801

52. Niaura R, Poulas K, Kouretas D, Barbouni A, Tsatsakis A, Farsalinos K, Vantarakis A, Houezec L (2020) Nicotine and SARS-CoV-2: COVID-19 may be a disease of the nicotinic cholinergic system. Toxicology Rep 7:658-663. https://doi. org/10.1016/j.toxrep.2020.04.012

Publisher's Note Springer Nature remains neutral with regard to jurisdictional claims in published maps and institutional affiliations. 